\title{
An Empirical Study to Examine the Effect of Realistic Job Preview on Expectancies, Personal Goals and Performance
}

\author{
Hanadi Mohammed Chehade ${ }^{1} \&$ Said Taan EL Hajjar ${ }^{2}$ \\ ${ }^{1}$ College of Business, Ahlia University, Manama, Bahrain \\ ${ }^{2}$ College of Arts, Science \& Education, Ahlia University, Manama, Bahrain \\ Correspondence: Said T. EL Hajjar, College of Arts, Science \& Education, Ahlia University, P. O. BOX: 10878, \\ Manama, Bahrain. Tel: 973-363-224-93. E-mail: salhajjar@ahlia.edu.bh
}

Received: November 14, 2015

Accepted: December 28, 2015 Online Published: January 23, 2016

doi:10.5539/ijbm.v11n2p164

URL: http://dx.doi.org/10.5539/ijbm.v11n2p164

\begin{abstract}
Several research studies confirmed that the administration of job preview information (J.P.I) guides to such desirable organizational outcomes as augmented satisfaction and reduced firing among new employees. Fewer studies have discovered the effects that J.P.Is hold other outcome variables such as attrition from the recruitment process, managerial commitment, and performance. The purpose of the present paper discovers the influences of J.P.I on outcome expectations and on performance through personal goals. An empirical study takes the opportunity to implement this case study on two well-known communication companies in the Kingdom of Bahrain that explores the effect of Management people on the relationship between expectancies and job achievement. The results of the Chi -square tests partially support the main hypothesis of this study which asserts that expectancies and goals that individuals set for themselves are not independent.
\end{abstract}

Keywords: expectancies, performance, personal goals, realistic job preview, self-efficacy

\section{Introduction}

Realistic job previews information (R.J.P) are any method an agency or business uses to help prospective employees get a balanced picture of the positive and negative aspects of work they will be doing and the organizational climate, prior to the offer of a position. This is important in "hidden" industries such as human services where many people may not have any information about the tasks and responsibilities of the job. An accurate R.J.P, combined with opportunities for prospective employees to choose not to go further in pursuing a job, can reduce turnover and hiring and training group of people who do not want the kind of work the agency has to offer. It is critical that the prospective newcomer be informed that the reason they are participating in a R.J.P is to help them make a decision about whether this company and this job is a good match for them. This needs to happen before a job offer has been made and should allow an opportunity for the prospective employee to decide that they do not wish to continue the application process. In addition, agency should take the opportunity to identify what makes them unique and why someone should work for them rather than for another agency.

Theory proposes that R.J.Ps should guide to developments in performance, but the overall results relating to the potential effects of JPIs on performance and the capability-performance relationship are conflicting and inconclusive. Additionally, reasonable explanations for these results are rarely explored. Clearly, additional research is necessary in order to interpret whether or not an effect actually exists and to explore explanations for why the results are inconsistent.

The purpose of this paper is to examine these issues from a wider point of view to address the general question of how outcome expectancies influence achievement or performance. More specifically, it is suggested that aspects of both personal goal theory and outcome expectancy theory can be applied to clarify how outcome expectancies influence performance. The main purpose of the study is to explore whether the information communicated about a job could influence the outcome expectancies individuals form about that job and definitively the performance goals that these individuals would set for themselves. By testing such hypotheses in a J.P.I context, it may be possible to uncover some explanations for the inconsistencies and lack of effects of J.P.Is on performance. More specifically, this study will essentially explore the effects of the J.P.I as a 
motivational factor by testing the potential influence of the J.P.I on personal goals.

The present study attempted to make some contributions on the literature, theory, and practice concerning J.P.Is, outcome expectancies, and personal goals. As mentioned above, the main objective of this study is to explore whether information about a job could influence the performance goals that individuals set via the expectancies that these individuals have formed based on the information. Many scientists discussed the effect of job preview information on job performance. Some of them ensured this influence while other denied it. To solve this conflict, this study will investigate the effect of human resources on job performance through two telephone companies (Zain \& Batelco) in the kingdom of Bahrain. It will study the effect of the types of R.J.P on expectancies, and the role that personal goal setting would play among the types of expectancies and job performance.

By investigating this question, potential reasons for the discrepant and inconsistent findings in the job preview information or simply R.J.P literature were expected to be revealed. A survey study about these two companies would clarify the aim of this paper. An analysis for this survey would be done using descriptive statistics and Chi-square results would be obtained for job preview information and its influence on outcome expectancies, for outcome expectancies and their influence on performance, and for personal goals and their mediating role between outcome expectations and performance.

\section{Historical Overview on J.P.Is}

Researchers found no performance differences between individuals who received a realistic job preview or in another word J.P.I (experimental group) and individuals who did not (control group) (Wanous, 1973; Youngberg, 1963). It is actually found that R.J.P recipients demonstrate a slightly lower $(\mathrm{p}<0.10)$ performance level than their control group counterparts (Macedonia, 1969). While a researcher admits that there does not appear to be a significant effect of R.J.P on performance (Wanous, 1978). He points out that there could be some flaws and confounds in the aforementioned research studies that could account for the lack of R.J.P effects.

A few studies have exposed that R.J.Ps can have a significant and positive influence on job performance. In meta-analyses conducted by researchers, R.J.Ps were found to have a positive impact on performance (Premack \& Wanous, 1985; Phillips, 1998). However, this effect was dependent upon the medium by which the R.J.P was delivered.

Consistent with the previous research on this topic, written R.J.Ps had either a small negative effect on performance (Premack \& Wanous, 1985) or no effect on performance (Phillips 1998), and verbal R.J.Ps had no consistent effect on performance (Phillips, 1998), Whereas the majority of the research results have reported that there is no relationship between R.J.Ps and performance, the theoretical background supporting the argument that RJPs should have a positive influence on performance is strong.

It has been suggested that R.J.Ps should lead to improvements in performance because complete and thorough information about a job, like the information normally included in an R.J.P, should work through expectations to clarify work roles and help individuals perform at a higher level (Wanous, 1978). Wanous also suggests that an R.J.P may function as a motivational factor that could moderate the ability-performance relationship.

A researcher recognized that with respect to the effectiveness of R.J.Ps, two camps have emerged (Breaugh, 1983). Some researchers argue that R.J.Ps lead to beneficial organizational outcomes such as increased satisfaction and decreased turnover e.g. (Dugoni \& Ilgen, 1981). Other researchers conclude that there is little basis on which to argue that R.J.Ps have such beneficial effects e.g. (Schwab, 1981). It is likely that the poor design of the studies and lack of statistical power (due to small sample sizes) are the reasons for the weak and ambiguous results. It was also suggested that the timing of the R.J.P may have an impact on its effectiveness (Breaugh, 1983).

Depending on when the R.J.P is given during the process, any of the four psychological explanations for why R.J.Ps work may be appropriate (Breaugh, 1983). He also explains that in addition to the psychological processes used to explain the potential effectiveness of R.J.Ps (i.e. et expectations, improved ability to cope, air of honesty, and self-selection), boundary conditions of the R.J.P context must also be considered when building a theoretical framework for future research. It was suggested that certain boundary conditions must be met in order for R.J.Ps to have their maximum effect (Wanous, 1978). Specifically, he suggests that effectiveness of R.J.Ps might be limited when selection ratios are high, when the job is not an entry-level position, or when the unemployment rate is high. Researchers must consider how these situational characteristic could affect the actions of their subjects.

Performing manipulation checks, considering the timing of the R.J.P, testing the effects of the R.J.P on variables other than turnover, and conceptualizing R.J.Ps as persuasive communication are also suggestions made by the 
author. Most of these suggestions were considered in the present paper.

In the most recent study pertaining to R.J.Ps, researchers explored the interactive effects of need for cognition (N.F.C), message framing, and source credibility in the processing of realistic job information (Buda \& Charnov, 2003). The authors propose that different people may receive and process R.J.P information in different ways because of individual differences in cognitive styles. While it was touched upon this idea, researchers have not empirically tested such a proposition (Phillips, 1998). In past research, all participants have been treated the same and there has been no consideration of individual cognitive differences. The results of some researchers study suggest that N.F.C could be a potential moderator of R.J.P effectiveness because there was a significant interaction between credibility of the R.J.P source and R.J.P framing was more salient for low N.F.C subjects (Buda \& Charnov, 2003). If the content is too negative, applicants may be scared away. If there is no negative content, the intended purpose of the R.J.P is defeated. It seems as if other individual attributes (such as need for achievement, conscientiousness, self-efficacy, etc.) could also have moderating effects. Such individual attributes were considered in the present study.

In summary, the overall support for an R.J.P is beneficial effect on organizational outcomes is questionable. Several of the aforementioned research efforts sought to demonstrate how R.J.Ps lower turnover and increase satisfaction and performance. However, it is important to keep in mind that many of the empirical findings are not statistically significant and when they are, the effect sizes and correlations are extremely low. Several of the suggestions for improved research design (including manipulation checks) and the examination of new variables (i.e. R.J.P medium) have been implemented in some of the more current R.J.P research. However, several suggestions have been ignored and many questions concerning R.J.Ps have gone unanswered. Some studies go so far as to suggest that R.J.Ps may have detrimental effects on organizational outcomes. Clearly, more sound and thorough research is necessary. This study focused on the lack of clarity in the results concerning the potential effects that an R.J.P has on performance. It took into consideration and incorporated several of the suggestions for improving R.J.P research. The present study also drew from other literature steams to help explain the inconsistencies in the R.J.P research findings. Specifically, goal setting was empirically investigated as a possible explanation for why R.J.Ps may yield a negative effect on performance.

\section{Zain Bahrain}

\subsection{Overview}

Zain Bahrain is the new name for a trusted telecommunications brand that has, over the last three years, swept Bahrain to top place with its innovative technological and marketing approach (Zain Bahrain/About us ).

Having entered the Bahrain market as the first company to break the telecoms monopoly, Zain Bahrain human resource has proved time and again that technological innovation paired with top-class customer service can win the race.

\subsection{Zain Bahrain Wins Top Human Resource Award}

Zain Bahrain, a leading telecom services provider in Bahrain, has won a top human resources (H.R) award, recognizing it as a leader in nurturing human capital development (Trade Arabia, 2009). Zain Bahrain is doing this through a well-planned H.R vision, extensive training programs and leadership development within its ranks, a statement said.

The award was conferred on Zain Bahrain by SMR Gulf, which organized the HRD Congress 2009 conference and exhibition in Bahrain in November this year.

Zain Bahrain's initiatives towards its human resources programs is a highly integrated program that is specifically designed to make it the workplace of choice by meeting the needs of employees and supporting the organization's mission, vision, and values. These are programs that make a major statement about the organizations and the kind of true partnership ZAIN BAHRAIN wants to have with all of its employees.

\section{Batelco (Bahrain Telecommunications Company)}

\subsection{Overview}

Batelco is the leading integrated communications' provider in the Kingdom of Bahrain and a company of reference among the region's key telecommunications players for innovation and customer experience.

Batelco serves both the corporate and consumer markets in the most liberalized and competitive environment in the Middle East Africa region. It delivers cutting-edge fixed and wireless telecommunications services to its customers in Bahrain. 
Batelco offers end-to-end telecommunications solutions for its residential, business and government customers in Bahrain on Next Generation, all IP fixed and 3.5G wireless Broadband networks, MPLS based regional data solutions and GSM mobile ( Batelco Bahrain / About Us).

\subsection{Batelco Awarded "Telecoms Company of the Year 2009" at Prestigious Regional Event}

Batelco was awarded the Telecoms Company of the Year across the Middle East Region at the annual Arabian Business Achievements Awards 2009 ceremony held in Dubai under the Patronage of HH Sheikh Hamdan Bin Mohammed Bin Rashed Al Maktoum Crown Prince of Dubai (December, 2009).

Each year, the Awards, judged by eminent regional business and telecom executives, celebrate the very best in business performance, both on a corporate and individual level.

Batelco becomes one of the famous telecommunication companies in the Middle East and it is a leading regional company of reference, value and delivering innovation. During implementation Gulf HR includes the facility of on-site training. This is aimed at increasing Batelco clients' proficiency and utilizing the H.R and Payroll software effectively on a daily basis. It is provided by Batelco implementation consultants and includes the provision of the Gulf H.R training manuals which have been specifically developed for this purpose.

Overall, there is no doubt that the H.Rs at Zain Bahrain and Batelco Bahrain are successful ones but based on the sample data it seems that there is a lack in the interest of the task-self efficacy expectancies and its effect on the issues of hiring new employees which would be beneficial for H.R. It will also help administrators of job preview information to make better selection of workers. It is a fact that selecting individuals with high quality will bring credit on future performance of the institution by developing productivity.

\section{Hypothesis Description}

Based on the review of previews research concerning realistic job previews, expectancy theory, and goal setting theory, the following hypotheses were formulated:

Hypothesis 1a: The type of job preview information will directly influence personal outcome expectancies.

Several empirical studies support the claim that R.J.Ps lower outcome expectations (Avner, Guastello, \& Alderman, 1982; Hom, Griffeth, Palich, \& Bracker, 1998). Some researchers found that the framing of the RJP message has a significant effect on expectations (Buda \& Charnov, 2003).Testing this hypothesis will serve as a manipulation check to confirm that the R.J.P works as intended by the researcher.

Hypothesis 1b: The type of job preview information will directly influence task self-efficacy expectancies. Individuals receiving either a negatively skewed job preview or a balanced realistic job preview will report significantly lower outcome expectancies than individuals who do not receive a realistic job preview (control group).

The work of some researchers can also be applied in support of this hypothesis, for the authors do not specify what type of expectancies are influenced by framing the job preview messages positively and negatively (Buda, \& Charnov 2003). Likewise, several other researchers have demonstrated how an R.J.P can lower expectations about a job, but the type of expectation is not always clear (Wanous, 1978; Dugoni \& Ilgen, 1981; Avner, Guastello, \& Alderman, 1982). Based on the work of a researcher, it is logical to assume that self-efficacy expectations, like outcome expectations, will also be lowered in response to the amount of negative information included in a job preview (Bandura, 1982).

Hypothesis 2a: Personal outcome expectancies will have a positive influence on the personal goals that individuals set for themselves. Higher outcome expectancies will lead to higher goals and lower expectancies will lead to lower goals.

Hypothesis 2b: Task self-efficacy expectancies will have a positive influence on the personal goals that individuals set for themselves. Higher task self-efficacy expectancies will lead to higher goals and lower expectancies will lead to lower goals.

Based on goal setting theory and social cognitive theory, the levels of expectations (or expectancies) are expected to predict the goal levels that individuals set for themselves (Bandura, 1982; Locke \& Latham, 1990). Moreover, several researchers have found that expectancies are the key determinant of the kind of goals that individuals will choose for themselves (Latham, Locke, \& Fassina 2002). Therefore, both types of expectancies were expected to influence goals.

Hypothesis 3a: Personal goals will play a facilitator role in the relationship between personal outcome expectancies and performance. Specifically, outcome expectancies predict performance through their influence 
on personal goals.

Hypothesis 3b: Personal goals will play a facilitator role in the relationship between task self-efficacy expectancies and performance. Specifically, task self-efficacy expectances predict performance through their influence on personal goals.

It is logical to presume that goals would play an important role in the relationship between outcome expectancies and performance. Researchers manipulated the normative information that individuals receive about a job by varying the goals they assigned to participants. They found that the normative information that individuals inferred from the assigned goals influenced the performance expectancy (i.e. the personal outcome expectancy in the present study), which then influenced goals, which then influenced performance.

\section{Rationale for the Study}

To summarize, the results concerning the effects of realistic job preview on performance and satisfaction are inconsistent. The following model (Figure 1) was developed in this study to illustrate how R.J.Ps influence the two types of outcome expectancies (O.E): personal outcome expectancies (P.O.E) and Task-self efficacy expectancies (T.S.E.E), which influence the personal goals (P.G) of the employees that lead to performance and satisfaction. Self-efficacy, need for achievement, and self-esteem were expected to moderate the relationship between expectancies and goals and the relationship between expectancies and performance. This theoretical model (Figure 1) will be tested in the present paper, as an initial step in developing and revising the model for further research investigations.

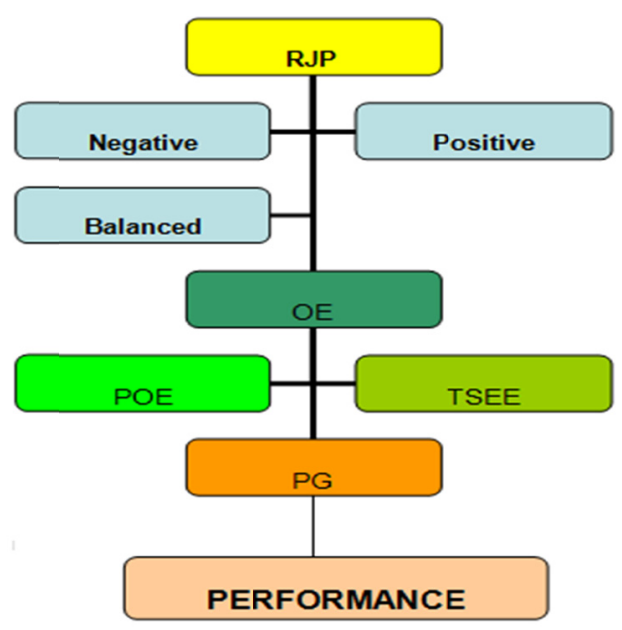

Figure 1. Realistic job preview model

\section{Data Analysis and Interpretation}

The term analysis refers to the computation of certain measures along with searching for patterns of relationship that exists among data groups. Thus in the process of analysis, relationships or differences supporting or conflicting with original or new hypothesis should be subjected to statistical tests of significance to determine with what validity data can be said to indicate any conclusions.

The study is conducted among employees in Zain \& Batelco companies in Bahrain. Questionnaire method is used for collecting primary data. Seventeen questions were included for collecting information on various types of realistic job preview, expectancies, performance and personal goals. It included questions to clarify their effectiveness on each other. The sampling unit is type of realistic job preview. Questionnaire method is used for collecting primary data. 17 questions were included for collecting information on various types of realistic job preview (RJP), expectancies, performance and personal goals. A random sample of 65 employees is collected from the two companies Batelco and Zain in the kingdom of Bahrain. Participants in the main study were six individuals who had visited employments at Batelco and Zain. However, 40 participants of these two companies completed an informed consent form (Appendix A) prior to participating in the study. 


\subsection{Comparative Preview Information Bar Chart}

The following bar chart describes in percent how forty query employees at Batelco and Zain perceived the preview information provided to them about the job and task.

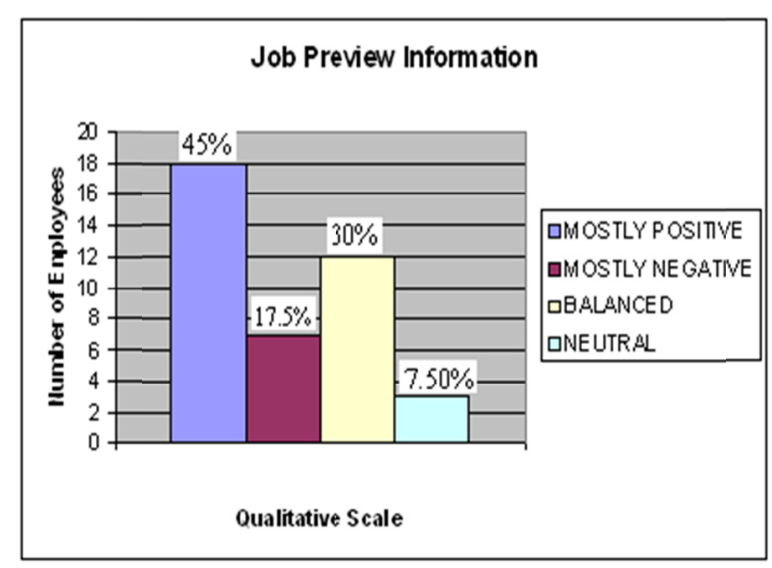

Figure 2. Job preview information

The comparison indicates that most of the employees (about $93 \%=45 \%+17.5 \%+30 \%$ ) in the two companies were perceived job preview information (mostly positive, mostly negative and Balanced) about the job. $75 \%$ ( $45 \%$ $+30 \%$ ) of the employee perceived mostly positive or balanced preview information about the job which means that the human resources in the two companies were approximately encouraging people at the beginning of their works. Also the analysis of the questionnaire will be significant because an important number of 37 employees out of 40 were perceived job preview information whether it is negative, positive or both as indicated in Figure 2.

\subsection{Questionnaire Evaluation and Interpretation}

Pie charts are used to describe the evaluation of each construct in the questionnaire, and each chart is followed by a statistical interpretation.

7.2.1 Being Provided With Preview Information about the Job Will Have a Direct Effect on Outcome Expectations

Figure 3 describes in percent the effect of R.J.B on Outcome Expectations.

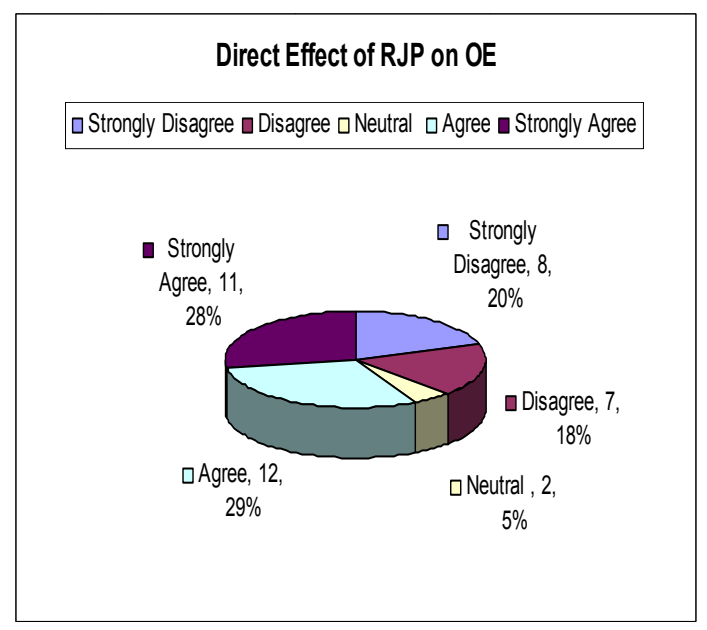

Figure 3. Direct Effect of RJP on outcome expectations 
$57 \%$ of the employees have agreement, whether it is strong or not, that providing employees with preview information about the job will have a direct effect on their outcome expectations. This indicates that realistic job previews influences the outcome expectancies.

7.2.2 Individuals Receiving Positively Job Preview Information will Report Significantly Higher Outcome Expectations

Figure 4 describes in percent the positive effect of R.J.B on increasing Outcome Expectations.

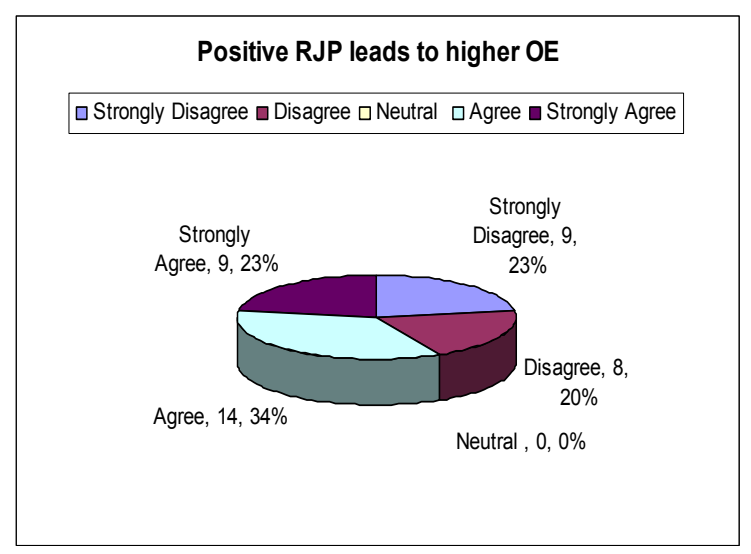

Figure 4. Positive RJP report higher outcome expectations

Although $57 \%$ of the employees have agreement, whether it is strong or not, that providing employees with positive job preview information will report higher outcome expectations, the other $43 \%$ of the employees contradict them, which is also a remarkable number. So this indicates that positive realistic job preview tends to report higher outcome expectancies than lowering them.

7.2.3 Individuals Receiving Either Negatively or Balanced Job Preview Information will Report Significantly Lower Outcome Expectations

Figure 5 describes in percent how the negative or balanced R.J.P impacts in decreasing outcome expectations.

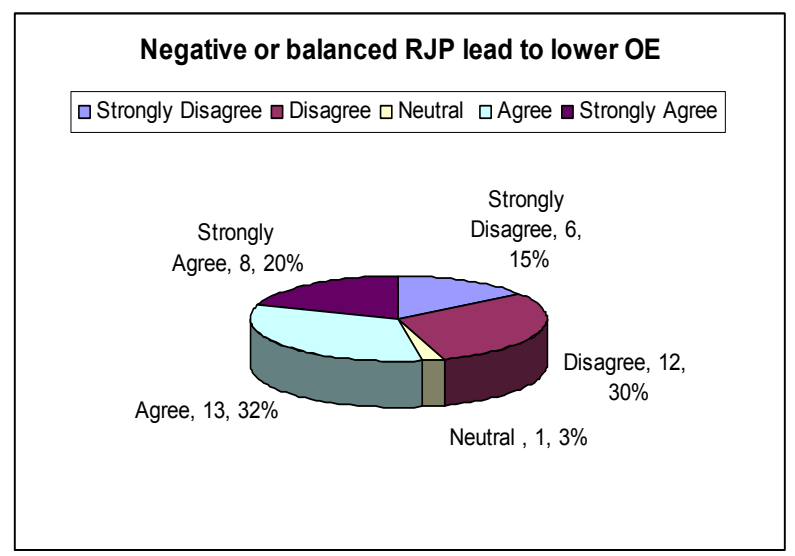

Figure 5. Negative or balanced RJP report lower outcome expectations

Although $52 \%$ of the employees have agreement, whether it is strong or not, that providing employees with negative or balanced job preview information will report lower outcome expectations, the other $45 \%$ of the employees contradict them, which is also a remarkable number. So this indicates that negative or balanced realistic job preview tend to report lower outcome expectancies than higher them. As a result, charts $3 \& 4$ have demonstrated how an RJP can higher or lower expectations about a job, but the type of expectation is not always 
clear. Therefore, these results deserve to be tested. A sample of 32 individuals is selected and a contingency analysis table has been constructed from data obtained through the two companies in which respondents were asked to indicate whether they received a positive job preview or a negative or balanced one and whether RJP higher or lower outcome expectations. The following contingency table is provided.

Table 1. R.J.P observed values

\begin{tabular}{lll}
\hline Type of RJP & Higher OE & Lower OE \\
\hline Positive & 10 & 5 \\
Negative or balanced & 8 & 9 \\
\hline
\end{tabular}

\section{Descriptive Statistics}

The following output and the similar coming outputs are obtained through Excel. Open an Excel sheet, fill the data and then go to Data / Data Analysis / Data Descriptive. The aim of this output is to get the sample mean $x$ and the sample standard deviation $\sigma$ of the data distribution. $x$ is defined by the formula:

$$
\bar{x}=\frac{\sum x}{n}
$$

Where $\mathrm{n}$ is the number of observations and $\mathrm{x}$ is a certain observed member in the data. It calculates the average of the obtained data entries. $\sigma$ is defined by the formula:

$$
\sigma=\sqrt{\frac{\sum(x-\bar{x})^{2}}{n-1}}
$$

Its value describes the variations of the data entries from the mean. There is no need to use these formulas because the Excel does the job.

Table 2. R.J.P descriptive statistics

\begin{tabular}{lcll}
\hline Column1 & \multicolumn{3}{l}{ Column 2} \\
\hline Mean & 9 & Mean & 7 \\
Standard Error & 1 & Standard Error & 2 \\
Median & 9 & Median & 7 \\
Standard Deviation & 1.41421356 & Standard Deviation & 2.8284271 \\
Sample Variance & 2 & Sample Variance & 8 \\
Range & 2 & Range & 4 \\
Minimum & 8 & Minimum & 5 \\
Maximum & 10 & Maximum & 9 \\
Sum & 18 & Sum & 14 \\
Count & 2 & Count & 2 \\
\hline
\end{tabular}

These results allow us to conclude that individuals that receive R.J.Ps tend to lead higher outcome expectancies then lowering it.

We are going to use the chi-square approach to test this result i.e. Types of realistic job preview are not independent of outcome expectations. The test uses a significance level equal to 0.05 .

\section{Contingency Analysis (Independence and Homogeneity)}

A contingency table (or two-way frequency table) is a table in which frequencies correspond to two variables (on variable is used to categorize rows, and a second variable is used to categorize columns). Contingency tables are especially important because they are often used to analyze survey results. A test of independence tests the null hypothesis that the row variable and the column variable in a contingency table are not related. (The null hypothesis is the statement that the row and column variables are independent). 
The null hypothesis (denoted by $\mathrm{H}_{0}$ ) is a statement assumed true unless it is false. The alternative hypothesis (denoted by $\mathrm{H}_{\mathrm{A}}$ ) is a statement that would be considered true if the null hypothesis is false.

Null Hypothesis $H_{0}$ : R.J.P are independent of outcome expectancies.

Alternative Hypothesis $H_{a}$ : R.J.P and outcome expectancies are not independent.

Table 3. RJP expected values

\begin{tabular}{llll}
\hline Type of RJP & Has effect & Has no effect & Total \\
\hline Positive & Observed $=12$ & Observed $=3$ & 15 \\
& Expected $=8.4$ & Expected $=6.6$ & \\
Negative or balanced & Observed $=6$ & Observed $=11$ & 17 \\
& Expected $=9.6$ & Expected $=7.4$ & \\
Total & 18 & 14 & 32 \\
\hline
\end{tabular}

Critical value of Chi-square $\left(\chi_{\alpha}^{2}\right)$ :

A critical value is the number on the borderline separating sample statistics that are likely to occur from those that are unlikely to occur.

Degree of freedom d.f. $=(c-1)(r-1)$ where $r$ is the number of rows and $\mathrm{c}$ is the number of columns. The number of degrees of freedom $(c-1)(r-1)$ reflects the fact that because we know the total of all frequencies in a contingency table, we can freely assign frequencies to only $\mathrm{r}-1$ rows and c-1 columns before the frequency for every cell is determined. So d.f. $=(2-1)(2-1)=1$, then using Appendix B, the critical value of Chi-square is:

$$
\chi_{\alpha}^{2}(1,0.05)=3.84146
$$

In a test of independence with a contingency table, the critical region (the shaded region where the null hypothesis is false) is located in the right tail only.

\section{Chi-square test statistic $\chi^{2}$ :}

The Chi-square test statistic is a value computed from the sample data that is used in making the decision about the rejection of the null hypothesis. It allows us to measure the degree of disagreement between the frequencies actually observed and those that we would theoretically expect when the two variables are independent. Small values of the $\chi^{2}$ test statistic result from close agreement between frequencies observed and frequencies expected with independent row and column variables. Large values of the $\chi^{2}$ test statistic are in the rightmost region of the Chi-square distribution, and they reflect significant differences between observed and expected frequencies.

$$
\chi^{2}=\sum \frac{\left(O_{i j}-E_{i j}\right)^{2}}{E_{i j}}=\frac{(12-8.4)^{2}}{8.4}+\frac{(3-6.6)^{2}}{6.6}+\frac{(6-9.6)^{2}}{9.6}+\frac{(11-7.4)^{2}}{7.4}=6.61
$$

Since $\chi^{2}=6.61>\chi_{\alpha}^{2}=3.84146$, then we reject $\mathrm{H}_{0}$. Based on this sample data there is a $95 \%$ confidence that the realistic job preview and the outcome expectancies are not independent. Hence, hypothesis $1 \mathrm{a}$ and hypothesis $1 \mathrm{~b}$ are satisfied.

\subsubsection{Individuals with Higher Personal Outcome Expectations will Lead to Higher Goals}

Figure 5 describes in percent how higher personal outcome expectations lead to higher goals. 


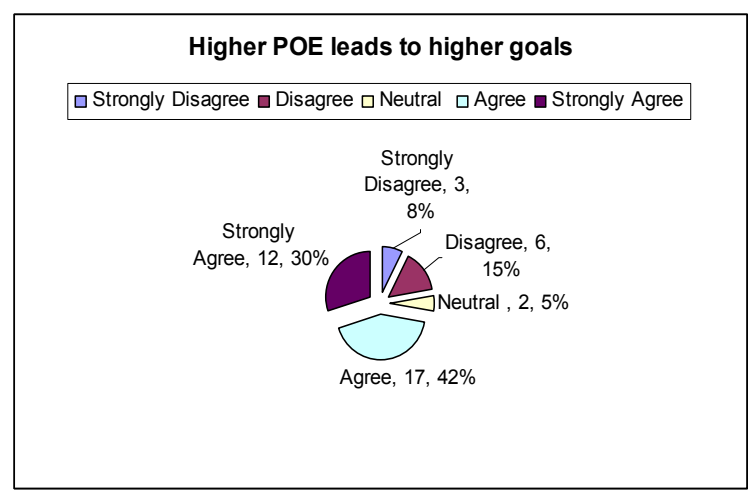

Figure 5. Higher personal outcome expectations lead to higher goals

$72 \%$ of the employees have agreement, whether it is strong or not, that employees with higher personal outcome expectations about the job will lead them to set higher goals. This indicates that individuals with higher personal outcome expectancies are expected to have higher predictions about their goal settings.

7.2.5 Individuals with Lower Personal Outcome Expectations will Lead to Lower Goals

Figure 6 describes in percent how lower personal outcome expectations lead to lower goals.

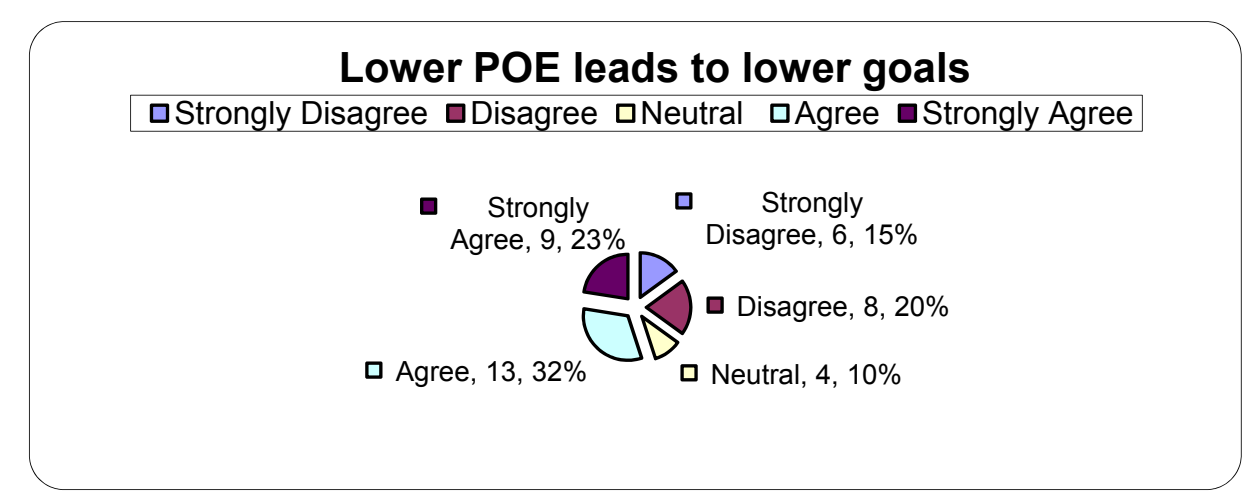

Figure 6. Lower personal outcome expectations lead to lower goals

$55 \%$ of the employees have agreement, whether it is strong or not, that employees with lower personal outcome expectations about the job will lead them to set lower goals. This indicates that individuals with lower personal outcome expectancies are expected to have lower predictions about their goal settings.

As a result, charts $5 \& 6$ prove that expectancies are the key determinant of the kind of goals that individuals will choose for themselves. That is both types of expectancies were expected to influence goals.

7.2.6 Individuals with Higher Task Self-Efficacy Expectations will Lead to Higher Goals

Figure 7 describes in percent how higher task self-efficacy expectations lead to higher goals. 


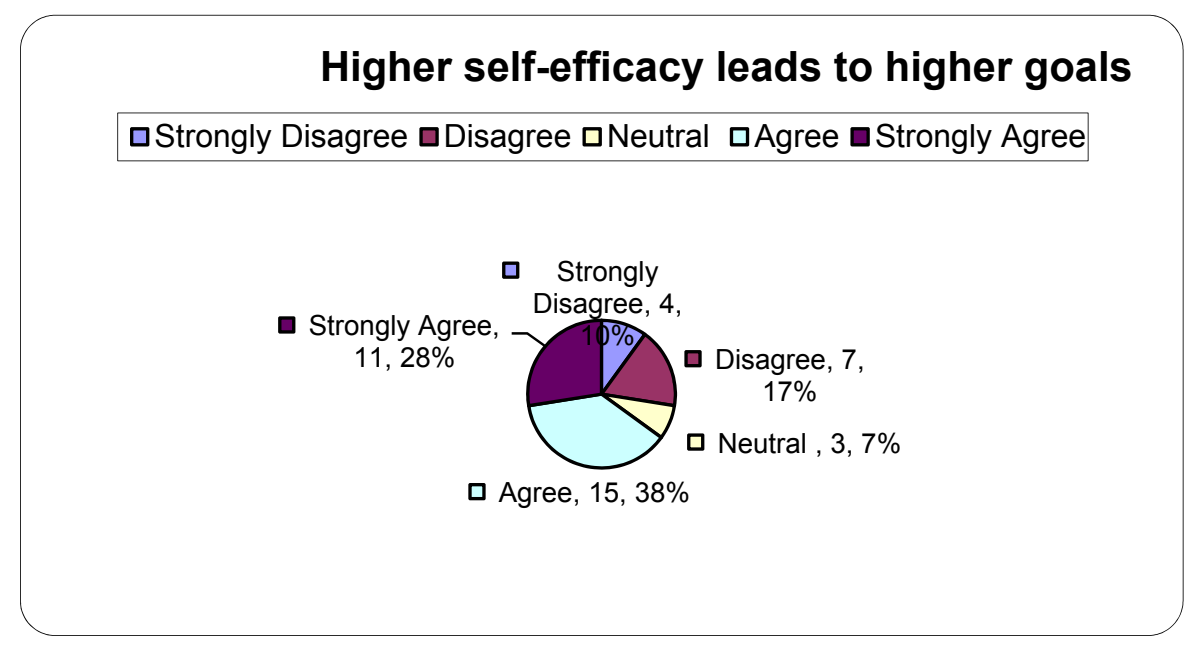

Figure 7. Higher task self-efficacy expectations lead to higher goals

$66 \%$ of the employees have agreement, whether it is strong or not, that employees with higher task self-efficacy expectations about the job will lead them to set higher goals. This indicates that individuals with higher self-efficacy outcome expectancies are expected to have higher predictions about their goal settings.

7.2.7 Individuals with Lower Task Self-Efficacy Expectations will Lead to Lower Goals

Figure 8 describes in percent how lower task self-efficacy expectations lead to lower goals.

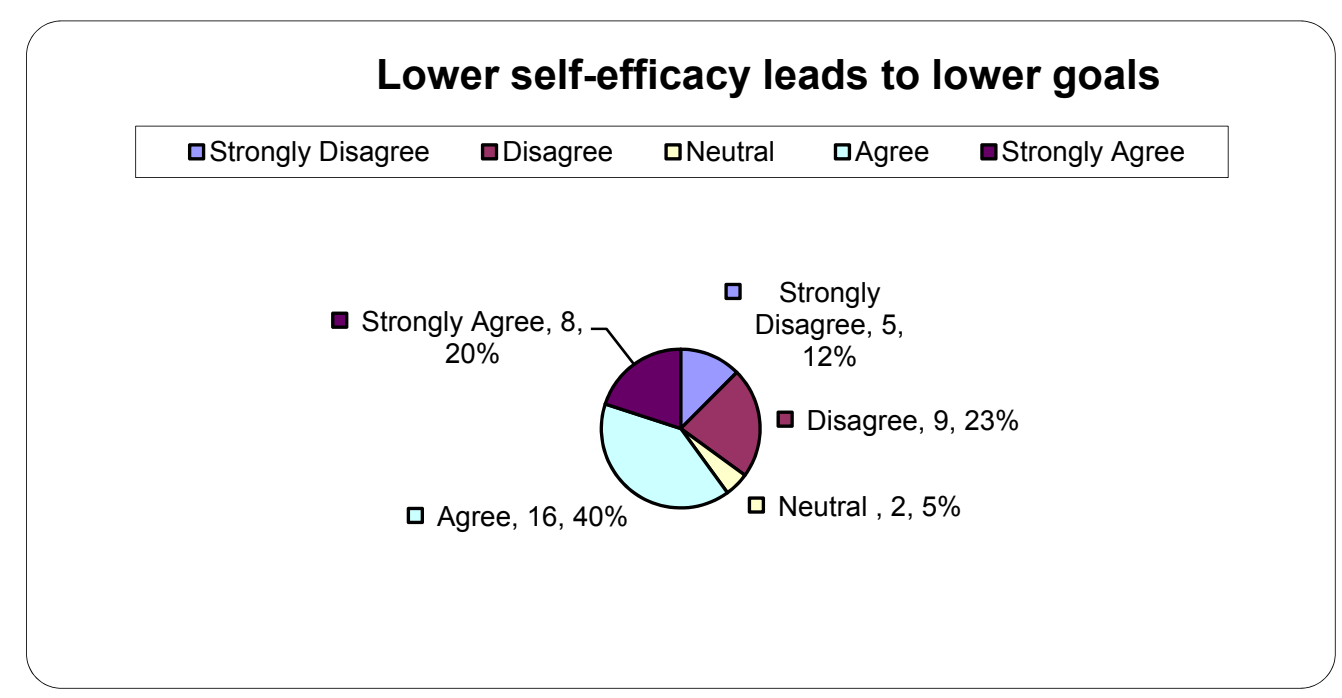

Figure 8. Lower task self-efficacy expectations lead to lower goals

$60 \%$ of the employees have agreement, whether it is strong or not, that employees with lower task self-efficacy expectations about the job will lead them to set lower goals. This indicates that individuals with lower self-efficacy outcome expectancies are expected to have lower predictions about their goal settings.

As a result, charts 5, 6,7\& 8 have demonstrated how outcome expectancies can higher or lower personal goals. To test this result, a sample of 32 individuals is selected and a contingency analysis table has been constructed from data obtained through the two companies in which respondents were asked to indicate which of the two types of expectancies higher or lower their personal goals. The following contingency table is provided. 
Table 4. OE descriptive statistics

\begin{tabular}{llll}
\hline Column 1 & & Column & \\
\hline Mean & 11.5 & Mean & 4.5 \\
Standard Error & 2.5 & Standard Error & 0.5 \\
Median & 11.5 & Median & 4.5 \\
Standard Deviation & 3.535533906 & Standard Deviation & 0.70710678 \\
Sample Variance & 12.5 & Sample Variance & 0.5 \\
Range & 5 & Range & 1 \\
Minimum & 9 & Minimum & 4 \\
Maximum & 14 & Maximum & 5 \\
Sum & 23 & Sum & 9 \\
Count & 2 & Count & 2 \\
\hline
\end{tabular}

These results allow us to conclude that individuals with outcome expectations tend to predict higher personal goals than lowering it.

We are going to use the chi-square approach to test this result i.e. types of outcome expectancies are not independent of personal goals. The test uses a significance level equal to 0.05 .

Contingency Analysis

Null Hypothesis $H_{0}$ : Outcome expectancies are independent of personal goals.

Alternative Hypothesis $H_{a \text { : }}$ Outcome expectancies and personal goals are not independent.

Table 5. OE expected values

\begin{tabular}{llll}
\hline Types of OE & Affect & Don't affect & Total \\
\hline POE & Observed $=11$ & Observed=3 & 14 \\
& Expected $=8.3$ & Expected $=5.7$ & \\
Self-efficacy & Observed $=8$ & Observed=10 & 18 \\
& Expected $=10.7$ & Expected=7.3 & \\
Total & 19 & 13 & 32 \\
\hline
\end{tabular}

Critical value of Chi-square $\left(\chi_{\alpha}^{2}\right)$ :

d.f. $=(\mathrm{c}-1)(\mathrm{r}-1)=(2-1)(2-1)=1$, then

$$
\chi_{\alpha}^{2}(1,0.05)=3.84146
$$

Chi-square test statistic $\chi^{2}$ :

$$
\chi^{2}=\sum \frac{\left(O_{i j}-E_{i j}\right)^{2}}{E_{i j}}=\frac{(11-8.3)^{2}}{8.3}+\frac{(8-10.7)^{2}}{10.7}+\frac{(3-5.7)^{2}}{5.7}+\frac{(10-7.3)^{2}}{7.3}=3.837199
$$

Since $\chi^{2}=3.837199<\chi_{\alpha}^{2}=3.84146$, then we don't reject $\mathrm{H}_{0}$. Based on this sample data there is a $95 \%$ confidence that the types of outcome expectancies and personal goals are independent. However, This result is not yet clear because $\chi^{2}=3.837199$ and $\chi_{\alpha}^{2}=3.84146$ are approximately equal. So by looking at the above contingency table, we may recognize that personal outcome expectancies $(78.57 \%)$ have more effect on personal goals rather than task self-efficacy $(55.55 \%)$. Hence, hypothesis $2 \mathrm{a}$ would be satisfied while hypothesis $2 \mathrm{~b}$ is somehow satisfied.

\subsubsection{Function of Personal Goals between Personal Outcome Expectancies and Performance}

Chart 9 describes in percent how personal goals play a facilitator role between POE and performance. 


\section{Personal Goals play a facilitator role between POE and} Performance

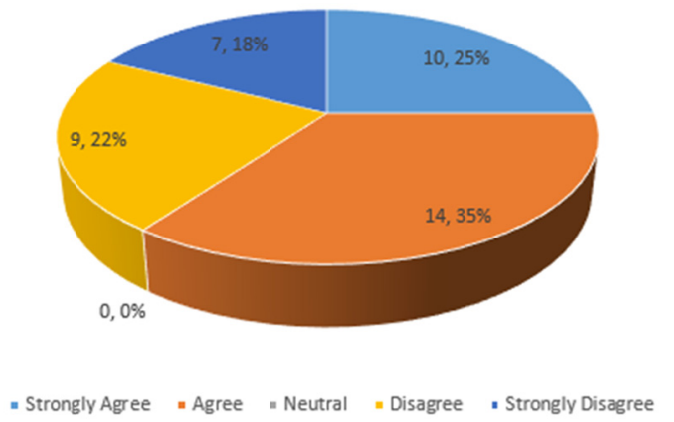

Figure 9. Personal goals play a facilitator role between POE and performance

$59 \%$ of the employees have agreement, whether it is strong or not, that employees personal goals play a facilitator role between their personal outcome expectations and their performance in work. This indicates personal outcome expectancies predict performance through their influence on personal goals.

\subsubsection{Function of Personal Goals between Task Self-Efficacy Expectancies and Performance}

Figure 10 describes in percent how personal goals play a facilitator role between self-efficacy and performance.

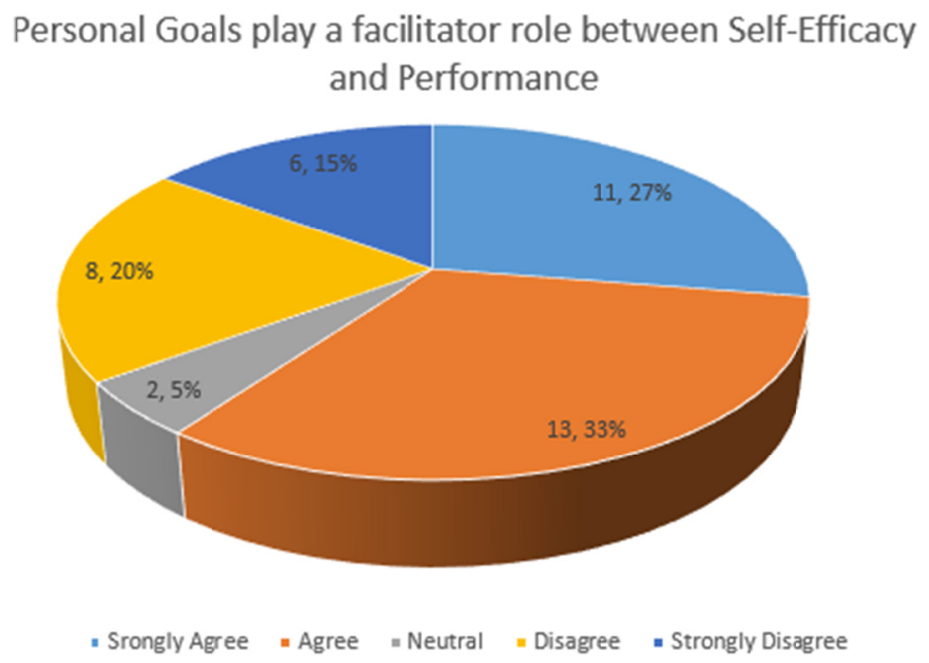

Figure 10. Personal goals play a facilitator role between self-efficacy and performance

$60 \%$ of the employees have agreement, whether it is strong or not, that personal goals play a facilitator role between their task self-efficacy expectations and their performance in work. This indicates task self-efficacy expectancies predict performance through their influence on personal goals.

As a result, charts $9 \& 10$ prove that personal goals play a facilitator role in the relationship between the two types of expectations and performance. To test this result, a sample of 32 individuals is selected and a contingency analysis table has been constructed from data obtained through the two companies in which respondents were asked to indicate whether personal goals play a facilitator role between their outcome expectations and their performance in work. The following contingency table is provided. 
Table 6. Expectancies and performance observed values

\begin{tabular}{lll}
\hline $\begin{array}{l}\text { Type of expectancies } \\
\text { and performance }\end{array}$ & Personal goals play a facilitator role & $\begin{array}{l}\text { Personal goals don't play a } \\
\text { facilitator role }\end{array}$ \\
\hline $\begin{array}{l}\text { Between personal outcome expectancies } \\
\text { and performance }\end{array}$ & 14 & 4 \\
$\begin{array}{l}\text { Between task self-efficacy expectancies } \\
\text { and performance }\end{array}$ & 5 & 9 \\
\hline
\end{tabular}

Table 7. Expectancies and performance descriptive statistics

\begin{tabular}{llll}
\hline Column 1 & \multicolumn{3}{c}{ Column 2 } \\
\hline Mean & 9.5 & Mean & 6.5 \\
Standard Error & 4.5 & Standard Error & 2.5 \\
Median & 9.5 & Median & 6.5 \\
Standard Deviation & 6.363961031 & Standard Deviation & 3.53553391 \\
Sample Variance & 40.5 & Sample Variance & 12.5 \\
Range & 9 & Range & 5 \\
Minimum & 5 & Minimum & 4 \\
Maximum & 14 & Maximum & 9 \\
Sum & 19 & Sum & 13 \\
Count & 2 & Count & 2 \\
\hline
\end{tabular}

These results allow us to conclude that individuals believe that personal goals play a facilitator role between outcome expectancies and performance. We are going to use the chi-square approach to test this result i.e. personal goals play a facilitator role between outcome expectations and performance. The test uses a significance level equal to 0.05 .

\section{Contingency Analysis}

Null Hypothesis $H_{0}$ : Personal goals do not play a facilitator role between outcome expectancies and performance.

Alternative Hypothesis $H_{a}$ : Personal goals play a facilitator role between outcome expectancies and performance.

Table 8. Expectancies and performance observed values

\begin{tabular}{llll}
\hline Type of exp. and perform. & P G play a facilitator role & $\begin{array}{l}\text { P G don't play a facilitator } \\
\text { role }\end{array}$ & Total \\
\hline Between POE and perform. & Obs. $=14$ & Obs. $=4$ & 18 \\
& Exp. $=10.7$ & Exp. $=7.3$ & 14 \\
Between TSEE and perform. & Obs. $=5$ & Obs. $=9$ & \\
& Exp. $=8.3$ & Exp. $=5.7$ & 32 \\
\hline
\end{tabular}

Critical value of Chi-square $\left(\chi_{\alpha}^{2}\right)$ :

d.f. $=(\mathrm{c}-1)(\mathrm{r}-1)=(2-1)(2-1)=1$,

$$
\chi_{\alpha}^{2}(1,0.05)=3.84146
$$

Chi-square test statistic $\chi^{2}$ :

$$
\chi^{2}=\Sigma \frac{\left(O_{i j}-E_{i j}\right)^{2}}{E_{i j}}=\frac{(14-10.7)^{2}}{10.7}+\frac{(5-8.3)^{2}}{8.3}+\frac{(4-7.3)^{2}}{7.3}+\frac{(9-5.7)^{2}}{5.7}=5.73211
$$

Since $\chi^{2}=5.73211>\chi_{\alpha}^{2}=3.84146$, then we reject $\mathrm{H}_{0}$. Based on this sample data there is a $95 \%$ confidence 
that personal goals play a facilitator role between outcome expectancies and performance. Hence, hypothesis $3 \mathrm{a}$ and hypothesis $3 \mathrm{~b}$ are satisfied.

7.2.9 Effect of Realistic Job Preview on Performance

Out of 40 employees in the two companies, 37 of them received job preview information. These respondents were asked to indicate, in general, whether their received job preview information affected their performance at work. The following contingency table is provided.

Table 9. Effect of RJP on performance

\begin{tabular}{llll}
\hline Type of RJP & Has effect on performance & Has no effect on performance & Total \\
\hline Positive & 12 & 6 & 18 \\
Negative & 3 & 4 & 7 \\
Balanced & 9 & 3 & 12 \\
Total & 24 & 13 & 37 \\
\hline
\end{tabular}

Table 10. Effect of RJP on performance descriptive statistics

\begin{tabular}{lcll}
\hline Column 1 & \multicolumn{3}{c}{ Column 2 } \\
\hline Mean & 7 & Mean & 3.666666667 \\
Standard Error & 3.511884584 & Standard Error & 1.666666667 \\
Median & 4 & Median & 2 \\
Standard Deviation & 6.08276253 & Standard Deviation & 2.886751346 \\
Sample Variance & 37 & Sample Variance & 8.333333333 \\
Range & 11 & Range & 5 \\
Minimum & 3 & Minimum & 2 \\
Maximum & 14 & Maximum & 7 \\
Sum & 21 & Sum & 11 \\
Count & 3 & Count & 3 \\
\hline
\end{tabular}

These results allow us to conclude that individuals believe that R.J.Ps affect their performance at work. A sample of 32 employees is chosen randomly. We are going to use the chi-square approach to test this result i.e. R.J.P and performance are not independent. The test uses a significance level equal to 0.05 .

\section{Contingency Analysis}

Null Hypothesis $H_{0}$ : RJPs and performance are independent.

Alternative Hypothesis $H_{a}$ : RJPs and performance are not independent.

Table 11. Effect of RJP on performance expected values

\begin{tabular}{llll}
\hline Types of RJP & Has effect & Has no effect & Total \\
\hline Positive & Obs. $=14$ & Obs. $=2$ & 16 \\
& Exp. $=10.5$ & Exp. $=5.5$ & \\
Negative & Obs. $=4$ & Obs. $=2$ & 6 \\
& Exp. $=3.9$ & Exp. $=2.1$ & \\
Balanced & Obs. $=3$ & Obs. $=7$ & 10 \\
& Exp. $=6.6$ & Exp. $=3.4$ & \\
Total & 21 & 11 & 32 \\
\hline
\end{tabular}

Critical value of Chi-square $\left(\chi^{2}{ }_{\alpha}\right)$ :

$$
\begin{aligned}
& \text { d.f. }=(\mathrm{c}-1)(\mathrm{r}-1)=(2-1)(3-1)=2, \text { then } \\
& \chi_{\alpha}^{2}(2,0.05)=5.99147
\end{aligned}
$$


Chi-square test statistic $\chi^{2}$ :

$$
\chi^{2}=\Sigma \frac{\left(O_{i j}-E_{i j}\right)^{2}}{E_{i j}}=\frac{(14-10.5)^{2}}{10.5}+\frac{(4-3.9)^{2}}{3.9}+\frac{(3-6.6)^{2}}{6.6}+\frac{(2-5.5)^{2}}{5.5}+\frac{(2-2.1)^{2}}{2.1}+\frac{(7-3.4)^{2}}{3.4}=9.17666
$$

Since $\chi^{2}=9.17666>\chi_{\alpha}^{2}=5.99147$, then we reject $\mathrm{H}_{0}$. Based on this sample data there is a $95 \%$ confidence that, in general, realistic job previews and performance are related.

\subsection{Findings of the Study}

The result of hypothesis testing using Chi-square test indicates that realistic job previews are contributing towards performance satisfaction. The process of this contribution is described in the following model:

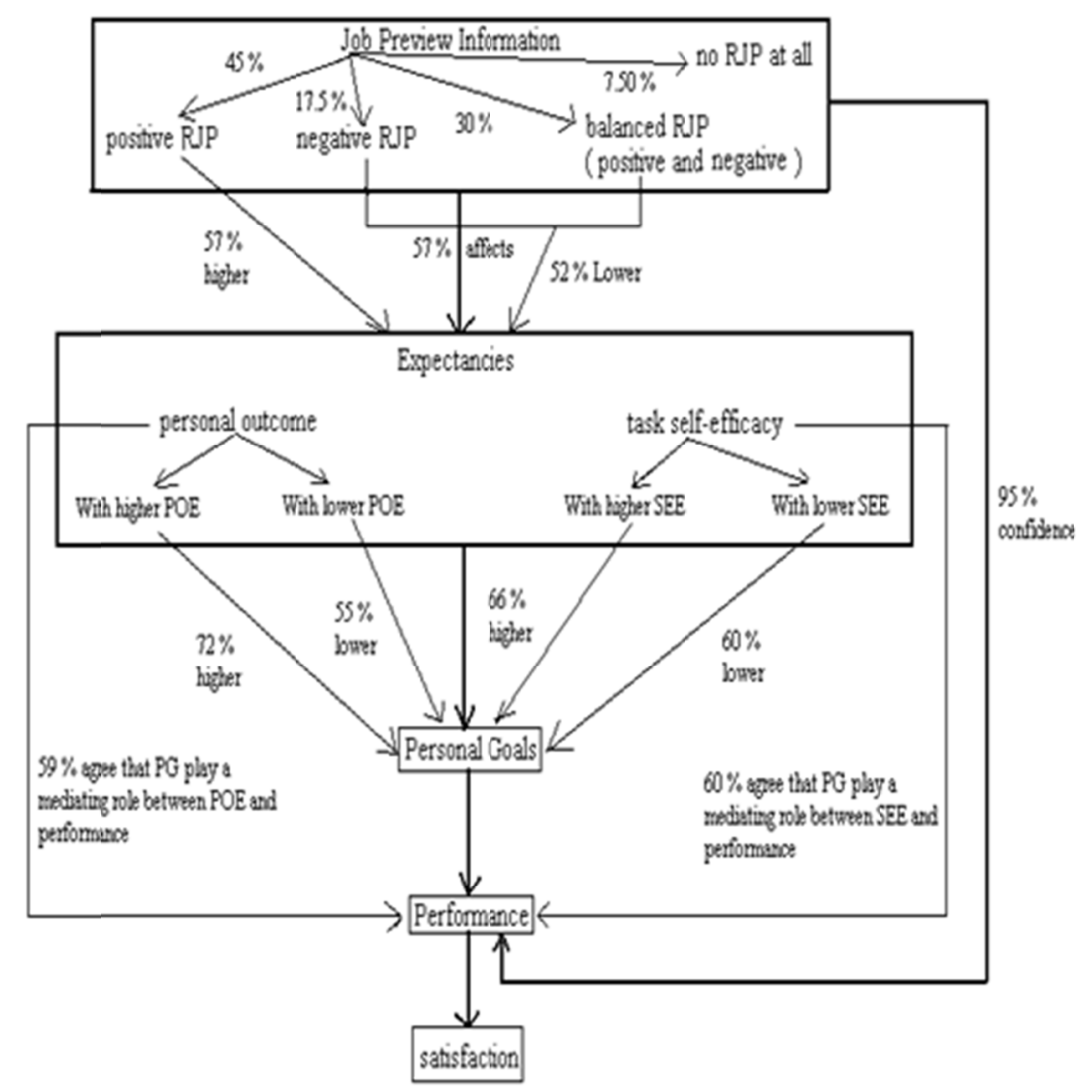

Figure 11. The Influence of R.J.P on O.E, goal settings, and performance

\subsection{Arrows Indicate Moderating Effects}

The model (Figure 11) shows that $57 \%$ of the employees agree that job preview information affects their outcome expectancies. Moreover, out of $45 \%$ of individuals who received positive R.J.P, $57 \%$ of them believe that R.J.P will lead to higher outcome expectations while out of $47.5 \%$ of the individuals who received negative or balanced R.J.P, $52 \%$ of them believe that RJP will lead to lower outcome expectancies. So in both cases, the effect of R.J.P on outcome expectancies is satisfied. RJP can higher or lower outcome expectancies. Individuals that receive positive R.J.Ps tend to lead higher outcome expectancies than lowering it. The Chi-square test used to clarify the effect of R.J.P on the outcome expectations gave $95 \%$ confidence that the realistic job preview and the outcome expectancies are related.

Outcome expectancies have also an effect on the personal goals set by individuals. $72 \%$ of respondents with higher P.O.E agree that their personal outcome expectations higher their personal goals while $55 \%$ of respondents with lower P.O.E agree that their personal outcome expectations lower their personal goals. Also 66\% 
of respondents with higher S.E.E agree that their task self-efficacy expectations higher their personal goals while $66 \%$ of respondents with lower S.E.E agree that their task self-efficacy expectations lower their personal goals. So in both cases, the effect of outcome expectancies on personal goals is satisfied. The O.E can higher or lowers personal goals. Individuals with higher P.O.E tend to lead higher personal goals than lowering it. But the Chi-square test used to clarify the effect of the two types of outcome expectations on personal goals gave $95 \%$ confidence that outcome expectancies and personal goals are almost not related $\left(\chi^{2}=3.837199 \approx \chi_{\alpha}^{2}=\right.$ 3.84146). So this hypothesis is not yet clear. However, the data obtained in the contingency table show that personal outcome expectations (78.57\%) affect personal goals, and also do task self-efficacy expectancies $(55.55 \%)$.

About $60 \%$ of the respondents agree that personal goals play a facilitator role between outcome expectancies and performance. Moreover, the Chi-square test used to support this result gave a $95 \%$ confidence that personal goals play an effective role between the two types of outcome expectancies and performance.

Over all these processes, there was a $95 \%$ confidence that, in general, realistic job previews and performance are related.

As a result, our findings show that the task of self-efficacy expectancies influence the objectives of hiring new staffs which could be beneficial for H.R. This will help administrators of realistic job preview to make better selection of workers. Selecting high quality workers will be reflected on future performance of the company by increasing productivity.

\section{Recommendations}

In addition to the importance of both goal setting theory and expectancy theory which can be applied to clarify how expectancies influence performance, it is best to administer the R.J.P early rather than late in the hiring process and that the optimal timing of an RJP may also depend on the intended purpose of the R.J.P. For example, if it is given too early, individuals may be scared away and there will be few applicants from which to select. When decreased earning is the objective, it may be best to present the R.J.P late, after individuals have been offered a job and have agreed to accept it.

The results we found that task self-efficacy expectancies influence goals suggest that it could be beneficial for H.R practitioners to consider how employee goals may be lowered by the administration of realistic job previews, or other H.R tools that might influence expectancies, which could then lead to lower performance levels. Practitioners may find it beneficial to incorporate some type of personal goals approaches in conjunction with R.J.P administration, in order to reap the benefits of R.J.Ps without the potential liability of lower performance. It may be possible to use personal goals as a motivational factor to increase performance following R.J.P administration.

The results obtained from the Chi-square tests also provide some useful suggestions to practitioners. The majority of responses from the data collected from the two companies (Batelco \& Zain) support the proposed hypotheses which suggest that job preview information may influence expectancies, which then influence personal goals and ultimately, performance. This data supports the need for H.R practitioners to consider the expectancies that their employees form about their jobs, and the goals that result from these expectancies.

\section{Conclusion}

The present study tries to make contributions to the literature, theory, and practice concerning realistic job previews, expectancies, and personal goals. One of the objectives of this study was to identify the reasons for the discrepant and inconsistent findings regarding performance in the R.J.P literature. The study was designed by using a combination of expectancy and personal goals theories to gather data and information. This will be used in testing hypotheses that predicted how job preview information would influence expectancies, goals, and ultimately performance. These predictions were partially supported by the results. One of the most interesting findings was the support for Hypotheses (3a) \& (3b), which predicted that goals would fully mediate the relationship between expectancies and performance. This finding adds to the continuous development of expectancy and personal goal theories. It also provides a reasonable explanation for how R.J.Ps can simultaneously lead to positive organizational outcomes such as increased satisfaction, decreased turnover, and negative organizational outcomes such as decreased performance. By identifying personal goals as an influential factor in the relationship between R.J.Ps, expectancies, and performance, practitioners may be able to develop more effective ways to use RJPs, to reduce turnover and increase satisfaction, while keeping performance as a desirable level. An obvious approach would be to incorporate personal goal techniques into R.J.P administration. Practitioners should also use personal goal techniques in conjunction with other H.R functions that influence 
employee expectancies. For example, it may be possible to apply the findings of the present study to training, performance appraisal, and compensation, as employees most likely form expectations about these H.R functions. Replication of this study in these and form other areas of human resources management is needed.

\section{References}

Avner B. K., Guastello S. J., \& Alderman, M. (1982). The Effect of a Realistic Job Preview on Expectancy and Voluntary versus Involuntary Turnover. Journal of Psychology, 11(1), 101-107.

Bandura, A. (1982). Self-Efficacy Mechanism in Human Agency. American Psychologist, 37(1), 122-147.

Breaugh, J. A. (1983). Realistic Job Previews: A Critical Appraisal and Future Research Directions. Academy of Management Review, 8(4), 612-619.

Buda, R., \& Charnov, B. H. (2003). Message Processing in the Realistic Recruitment Practices. Journal of Managerial, 15(1), 302-316.

Dugoni, B. L., \& Ilgen, D. R. (1981). Realistic Job Preview and the Adjustment of New Employees. Academy of Management Journal, 24(3), 579-591.

Hom, P. W., Griffeth, R.W., Palich, L. E., \& Bracker, J. S. (1998). An Exploratory Investigation into Theoretical Mechanisms Underlying Realistic Job Previews. Personnel Psychology, 51(1), 421-451.

Lathan, G. P., Locke, E. A., \& Fassina, N. E. (2002). High Performance Cycle: Standing the Test Time. The psychological management of individual performance. A handbook in the psychology of management in organizations. Chichester, England: Wiley, 201-228.

Locke, E. A., \& Latham, G. P. (1990). A Theory of Goal Setting and Task Performance. Englewood Cliffs, NJ: Prentice-Hall.

Macedonia, R. M. (1969). Expectations -Press and Survival. New York University.

Phillips, J. M. (1998). Effects of Realistic Job Previews on Multiple Organizational Outcomes: A Meta-Analysis. Academy of Management Journal, 41(6), 673-690.

Premack, S. L., \& Wanous, J. P. (1985). A Meta-Analysis of Realistic Job Preview Experiment. Journal of Applied Psychology, 70(1), 706-719.

Schwab, D. P. (1981). Review of Organizational Entry: Recruitment, Selection, and Socialization of Newcomers. Personal Psychology, 34(1), 167-170.

Wanous, J. P. (1973). Effects of a Realistic Job Preview on Job Acceptance, Job Attitudes, and Job Survival. Journal of Applied Psychology, 58(3), 327-332.

Wanous, J. P. (1978). Realistic Job Previews: Can a Procedure to Reduce Turnover also Influence the Relationship between Abilities and Performance? Personnel Psychology, 31(1), 249-258.

Youngberg, C. F. (1963). An Experimental Study of Job Satisfaction and Turnover in Relation to Job Expectations and Self Expectations. New York University, Business school Press.

\section{Appendix A}

\section{Questionnaire}

The following are questionnaires to study the impact of management people practices on the relationship between expectancies and job performance.

Instructions: Below are listed 5 statements that describe various things about the effectiveness among types of realistic job preview (RJPs), types of expectancies, personal goals and performance. We would like to know which of these statements you feel most accurately describe your own behavior when you are at work. Please select the response that best describes your own actions with respect to each statement.

Remember: There are no right or wrong answers. Please respond to each statement frankly. Your responses will be held in strict confidence.

\section{Response Scale:}

$1=$ Strongly Disagree 
$2=$ Disagree

$3=$ Neutral

4= Agree

$5=$ Strongly Agree

A. Effect of job preview information on outcome expectations

1. Being provided with preview information about the job will have a direct effect on outcome expectations.

$$
\begin{array}{lllll}
1 & 2 & 3 & 4 & 5
\end{array}
$$

2. Being proficient at work individuals receiving positively job preview information will report significantly higher outcome expectations.

$$
\begin{array}{lllll}
1 & 2 & 3 & 4 & 5
\end{array}
$$

3. Individuals receiving either negatively or balanced job preview information will report significantly lower outcome expectations.

$$
\begin{array}{lllll}
1 & 2 & 3 & 4 & 5
\end{array}
$$

\section{B. Effect of personal outcome expectations on goal settings}

4. Being proficient at work higher personal outcome expectations will lead to higher goals.

$$
\begin{array}{lllll}
1 & 2 & 3 & 4 & 5
\end{array}
$$

5. Being not proficient at work lower personal outcome expectations will lead to lower goals.

$$
\begin{array}{lllll}
1 & 2 & 3 & 4 & 5
\end{array}
$$

\section{Effect of task self-efficacy expectations on goal settings}

6. Being proficient at work higher task ability expectations will lead to higher goals.

$$
\begin{array}{lllll}
1 & 2 & 3 & 4 & 5
\end{array}
$$

7. Being not proficient at work lower task ability expectations will lead to lower goals.

$$
\begin{array}{lllll}
1 & 2 & 3 & 4 & 5
\end{array}
$$

\section{Function of personal goals between personal outcome expectancies and performance}

8. In setting my personal goals at work I will consider my expectations about the job.

$$
\begin{array}{lllll}
1 & 2 & 3 & 4 & 5
\end{array}
$$

E. Function of personal goals between self-efficacy expectancies and performance

9. In setting my personal goals at work I will consider my ability.
12

3
$4 \quad 5$

10. In setting my personal goals at work I will consider my previous job experience.
1

2
3
4
5

\section{F. Influence of job preview information on personal goals}

11. In setting my personal goals at work I will consider the job preview Information.
1
2
3
4
5

12. Overall, personal outcome expectation influences the goals that I set for myself.
1

2
3
4
5

13. Overall, Task self-efficacy expectation influences the goals that I set for myself.
$1 \quad 2 \quad 3$
4
5

14. Overall, personal goals play a mediating role between personal outcome expectations and my performance at work.

$$
\begin{array}{lllll}
1 & 2 & 3 & 4 & 5
\end{array}
$$

15. Overall, personal goals play a mediating role between task self-efficacy expectations and my performance at work. 


$\begin{array}{lllll}1 & 2 & 3 & 4 & 5\end{array}$

16. Overall, the information provided to me in the job preview information influences my performance at work.

$\begin{array}{lllll}1 & 2 & 3 & 4 & 5\end{array}$

17. Please indicate how you perceived the information provided to you about the job and task.

Mostly Positive

Mostly Negative

Both Positive and negative

Neutral

\section{Copyrights}

Copyright for this article is retained by the author(s), with first publication rights granted to the journal.

This is an open-access article distributed under the terms and conditions of the Creative Commons Attribution license (http://creativecommons.org/licenses/by/3.0/). 